\title{
Editorial
}

\section{Was Goliath blind or ignorant? The struggle between evidence and passion in alcohol public policies in Brazil}

\author{
Era Golias cego ou \\ ignorante? A luta entre a \\ evidência e a paixão nas \\ políticas públicas \\ para o consumo \\ de álcool no Brasil
}

It is a fairly known story: David, the wise and frail defendant of the Jews, had to face the gigantic Goliath in a battle in the valley of Elah to protect his people, their faiths and their beliefs. By using smart tricks such as blinding the giant with sand, or throwing pebbles at his face, David was able to subdue Goliath and obtain victory for his comrades. Not so simple though, when it comes to real life: when David meets Goliath other forces may be acting along. This editorial offers a snapshot of what is happening in the field - or valley - of policymaking and research experience in Brazil. Of course, we Brazilian psychiatrists and scientists are playing the "David" role in this scenario.

In November 2005, a public letter of intentions was produced during the $1^{\text {st }}$ Panamerican Conference on Alcohol Public Policies, organized by the Brazilian National Anti-Drug Secretariat. ${ }^{1}$ More than 100 representatives of about 27 countries from the Americas were present in this meeting. The letter had 6 recommendations: 1 ) that the prevention of harm from alcohol be a public health priority in the Americas; 2) that regional and national strategies towards reducing the harm from alcohol be developed, respecting cultural differences; 3) these strategies should be based on sound scientific evidence, based on research and exchange of information about the impact of such endeavors; 4) that a regional network should be created by member states under the supervision and collaboration of the Panamerican Health Organization to reduce alcohol-related harm; 5) that evidence-based policies should be implemented and evaluated in the Americas; and 6) priorities defined were: excessive drinking, overall alcohol consumption by the population, women and pregnancy, native Indian populations, youngsters and other vulnerable groups, violence, intentional and unintentional harm, alcohol consumption by minors, and alcohol-related problems. In fact, these recommendations are in consonance with the best current scientific evidence on the alcohol policy field.

As Babor and the Alcohol Policy Group have shown, ${ }^{2}$ strategies that work and do not work for alcohol reduction policies have been well studied, utilizing four criteria for their evaluation: 1) evidence of effectiveness - the quality of scientific information; 2) breadth of research support - quantity and consistency of the evidence; 3) testing across cultures, e.g. countries, regions, subgroups; 4) cost to implement and sustain - monetary and other costs. Based on these criteria, we already know which are the best cost-effective strategies: minimum legal purchase age, government monopoly of retail sales, restriction on hours or days of sale, outlet density restrictions, alcohol taxes, sobriety check points for drinking and driving, lowered blood alcohol content limits for drinking and driving, administrative license suspension, 
graduated licensing for novice drivers, and brief interventions for hazardous drinkers. The least effective practices are: voluntary codes of bar practice, promoting alcohol-free activities, alcohol education in schools, college student education, public service messages, warning labels, and designated drivers and ride services.

If, sponsored by the World Health Organization, these strategies have been clearly evaluated by a number of studies that point to clear cost-effective measures, why is it that they have not been implemented in Brazil? The answer may lie not in evidence, but in the passion (ideology) in addition to other external pressures (e.g. economic interests) that prevent policymakers to see clearly what is in front of them. The reality shows, for example, that treatment for drug and alcohol addiction works (evidence!) particularly when qualified professionals, using scientifically tested methodology act in an integrated system, allowing for ample access of patients to treatment. ${ }^{3}$

Priorities should be decided based on hard evidence. Evidence is derived from numbers. Numbers show that alcohol is clearly one of the most lethal psychoactive substances consumed in the world, ${ }^{4}$ but not the one which receives most attention with regard to public policy in Brazil. In some cases, alcohol impact can be reduced, as is the case of the city of Diadema. ${ }^{5}$ Alcohol is widely imbedded in our permissive culture, and Brazilian law only restricts alcohol advertising for beverages over $13 \%$ of alcohol content. Therefore, beers, "ice" drinks, "alcohol-pops", wines, and similar drinks are not controlled by such policy. This is why it is the authors' opinion that a change of focus is necessary with regard to the policy of treatment and prevention in Brazil. Policies should be based on staging prevention and treatment. This includes expanding the beds for inpatient treatment of acute effects of drug and alcohol abuse and dependence, instead of a continuous movement initiated by the government (passion!) to close psychiatric beds in the country - mostly due to ideology rather then hard evidence, as documented by recent clashes between David - the Brazilian Psychiatric Association, and Goliath - the Brazilian Ministry of Health.

The official policy of our Ministry of Health seems to privilege harm reduction practices - particularly those involved with HIVAIDS prevention and approach, day-hospitals (CAPS-AD), and the closure of psychiatric hospital beds. Is this blindness or ignorance? We have nothing against spending large amounts of money to support such policies - excluding the strange and passionate definition that psychiatric patients do not need hospital beds for parts of their treatment - alcoholics and drug abusers included. However, we are against such deviation of priorities, based exclusively on decisions made on arguments which are not driven by hard data. As such, the gigantic Goliath seems to wander in the desert, moving erratically in the direction that its master has decided. We are the weaker part that needs to face such giant, and it is the time to ask: do we have enough pebbles?

Flavio Pechansky

Center for Drug and Alcohol Research, Universidade Federal do Rio Grande do Sul (UFRGS), Porto Alegre (RS), Brazil

Ilana Pinsky, Ronaldo R Laranjeira Unidade de Pesquisa em Álcool e Outras Drogas (UNIAD, Alcohol and Drugs Research Unit), Department of Psychiatry, Universidade Federal de São Paulo (UNIFESP), São Paulo (SP), Brazil

Financing: FAPESP (Ilana Pinsky e Ronaldo Laranjeira), CNPq, SENAD, Janssen, Cristália (Ronaldo Laranjeira) Conflict of interests: None

\section{References}

1. National Anti-Drug Secretariat. Brasilia Declaration on Alcohol Public Policies. Brasilia, Brazil, Nov. 28-30, 2005. [cited 15 mar 2006]. Available at: www.ias.org.uk/resources/publications/theglobe/ globe0503 0601/gl0503 0601.pdf. p. 28-9

2. Babor T, Caetano R, Casswell S, Edwards G, Giesbrecht N, Graham K, Grube JW, Grunewald P, Hill L, Holder HD. Alcohol: no ordinary commodity. Oxford: Oxford University Press; 2003.

3. McLellan AT, Weinstein RL, Shen Q, Kendig C, Levine M. Improving continuity of care in a public addiction treatment system with clinical case management. Am J Addict. 2005;14(5):426-40.

4. Rehm J, Room R, Monteiro M, Gmel G, Graham K, Rehn N, Sempos $\mathrm{CT}$, Jernigan D. Alcohol as a risk factor for global burden of disease. Eur Addict Res. 2003;9(4):157-64.

5. Sergio Duailibi, William Ponicki, Joel Grube, Ilana Pinsky, Ronaldo Laranjeira, Martin Raw. Does restricting opening hours reduce alcohol related violence? Am J Public Health. 1. In press. 